publications such as these. I think there is, for two reasons.

First, in this age of computerized databases, none of these papers will go unnoticed by those who need to read them. Although none of the papers I read in the issues since the changeover were at the cutting-edge, they were all interesting and worthwhile.

Second, while these papers could undoubtedly all have found a home in specialized journals, the research library would be a much duller place as a result. Students would be denied the chance to stumble on journals that reflect the ex- uberance of the biological sciences as a whole. In short, if the Transactions and Proceedings save just a few budding biologists from joining the glassy-eyed ranks of the specialists, they will have served their purpose.

The revamping of these two journals has, I think, been successful. It has provided us with a stronger link to the time of science's bright morning.

Christopher Wills is in the Department of Biology, University of California, San Diego, La Jolla, California 92093, USA.

\title{
Botanical renaissance rag
}

\section{Philip Rubery}

The Plant Journal. Editors D. Bowles, M. Caboche, L. Dennis, D. Flavell, A. Komamine, J. Schell, C. Somerville and L. Willmitzer. Blackwell Scientific. 6/yr (12/yr in 1993). 1993 prices: UK £340, US and Canada $\$ 675$, elsewhere $£ 374$ (institutional); UK $£ 85$, US and Canada \$165, elsewhere £91 (personal). (Members' rates on application.)

THIS journal has the subtitle banner "For Cell and Molecular Biology" surmounting the photograph that dominates the front cover. The soil from which the green shoots of the journal emerged was the opportunity to approach plant biology 'in the round' - for the first time, according to the editors' preface to the inaugural issue in January 1991. Although the shades of Aristotle and Theophrastus might enjoy disputing this assertion, the contemporary point is that the sum of molecular and so-called 'classical' approaches exceeds their individual parts and is engendering a botanical renaissance. The editor's list of welcome disciplines runs the gamut from biochemistry to genetics, concluding "and, indeed, botany". It is a shame that botany has become almost a pejorative term; 'Plant Science' looks better on the departmental writing paper, and newspeak gets grants. 'Botany' derives from a Greek verb for pasture grazing

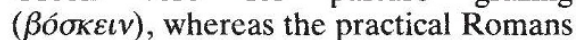
used the word for the sole of the foot (planta) to describe the shoot that it thrusts into the earth. (Which offers the more apposite metaphor for scientific funding practices?)

The broad range and high quality of the journal's contents so far justifies a quantitative measure of its success in moving from six to twelve issues per year in 1993. Its closest competitor is The Plant Cell, the stablemate of Plant Physiology, both owned by the American Society of Plant Physiologists (whose membership is debating a name change). Although there is interpenetration, authors' affiliations are predominantly North American in 'The Cell' and European in 'The Journal'. The majority of the papers concern genes one way or another, frequently making use of transgenic plants to do experiments that would have seemed fantastic only a few years ago. Two examples must suffice. From the first issue: the targeted expression of yeast invertase in vacuoles, cytoplasm and cell walls of tobacco

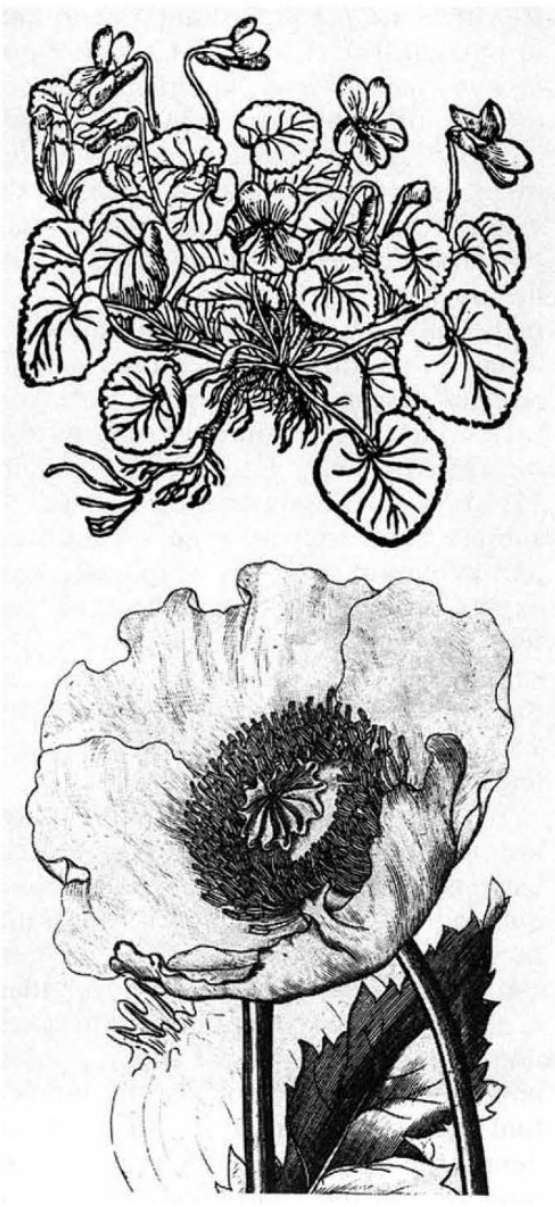

plants is used to investigate carbohydrate metabolism at the whole plant level. From the latest issue to hand: the differential suppression of carotenoid levels in tomato fruit (but not leaves) in plants that express antisense RNA to a gene involved in the later stages of phytoene biosynthesis. Important papers in other, less immediately genetic, fields include molecularly informed work on cell signalling and cell lineage.

The Plant Journal also carries "Technical Advance" reports and fairly substantial "Mini-Reviews". One in particular, by Jeffery Dangl, is a stimulating discussion of possible parallels between the genetic basis of plant disease resistance and the major histocompatibility complex of the mammalian immune system. The necessary explanation of the intricacies of antigen presentation and recognition is rendered more palatable than usual by an extended 'restaurant' metaphor which, after a brief period of digestion, left one hungry for more.

This journal is good value for time and money (especially to members of the Society for Experimental Biology, who get a discount) and can be recommended to individuals and to librarians.

Philip Rubery is in the Department of Biochemistry, University of Cambridge, Tennis Court Road, Cambridge CB2 1QW, UK.

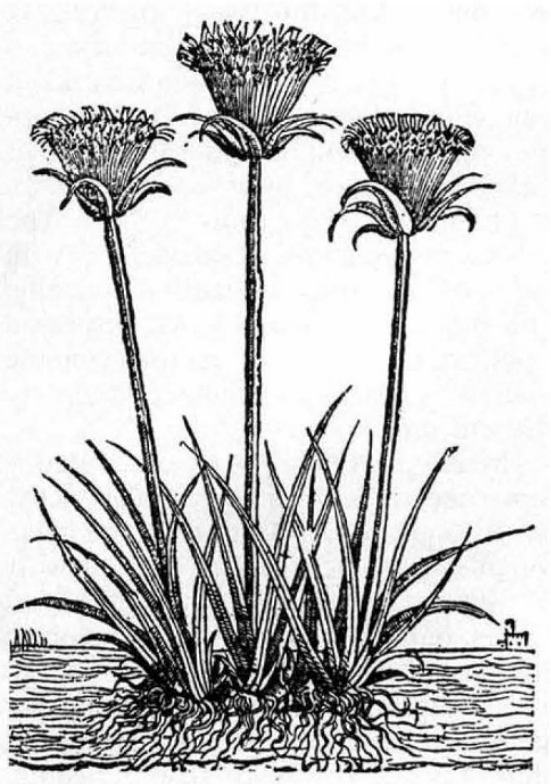

Plants In plctures - top left, white garden violet, Vlola flore albo; bottom left, poppy, Papaver somnlferum; above, paper reed, Papyrus nlloltca. 